\title{
Editorial
}

\section{Why brand? Some practical considerations for nation branding}

\section{LOOK BEFORE YOU LEAP}

What is it that makes the government of a country, a city or a region decide that it needs to 'work on its brand'? I have yet to come across a place that is actually happy with its image - although much of this discontent is, to borrow Maslow's (1965) definition, the 'low grumbles' of countries with highly developed economies and correspondingly highly developed expectations.

Probably the most common of these grumbles is that the image of the place is outdated and no longer useful for supporting its economic, political or developmental goals; but since the brand images of places naturally evolve at a very slow rate, this is an almost universal problem. Indeed, one of the most common reasons for place branding, especially for developing countries, is simply to prevent the image of the place from lagging too far behind its fast-changing reality.

Whatever the reason given, the governments (and often the people too) of most places appear to believe that there is a problem of some sort with their international image, but sometimes too little effort is expended in further identifying and analysing that image problem. The idea that a country has 'a negative reputation' becomes a commonplace, part of the 'groupthink', and governments often race off to find a solution before the problem has been properly understood.
It is a fundamental premise of any strategic task to be highly specific about the nature of the problem in order that the right strategy can be developed for dealing with it. It is also very important to make quite sure that there is a problem, and it is not simply an unfounded perception on the part of the country itself. Reading the domestic media in the UK, for example, it is clear that commentators from all political persuasions are convinced that Britain's international image is in shreds and tatters as a consequence of foot-and-mouth disease, mad cow disease, the invasion of Iraq, the terrorist bombs in London, the high cost and low standards of public transport, and so forth: yet the Anholt Nation Brands Index, which surveys over 25,000 people in 35 countries, shows that Britain is in fact one of the most highly regarded nations on the planet.

It is also important for countries to distinguish between negative reputation that matters and negative reputation that can be safely ignored because it has no consequences. A country may pour considerable resources into attempting to improve its brand image in another country where it is indeed held in low esteem: but if this country is not an important trading partner, nor likely to become one in the near future, nor has significant influence over other nations which are important partners or over international opinion in general, nor is it an important ally or source of talent or a 
partner in cultural relations or the home country of a significant diaspora, then the motivation to 'fix the brand' is mere vanity or hurt pride. And salving hurt national pride is not usually a valid motive for spending taxpayers' money.

So it must surely be the first stage of any responsible nation branding programme to take a good look at the current image of the place, and to make an assessment of exactly how and why it needs to be changed.

Different places need to work on their brands for different reasons.

\section{Introduction}

If the place is simply unknown to its target market, then it needs to be introduced - obviously concentrating on the sectors where it can deliver efficiently, profitably and sustainably.

\section{Targeting}

Some places are known, but to 'wrong' audiences which cannot help the place fulfil its ambitions - for example, people with too little or too much spending power. Here the brand needs to be targeted more accurately to the right countries, regions or cities, or to new demographic groups, business sectors or decision makers.

\section{Correction}

Some places are well known but for the wrong reasons, so the brand needs to be corrected. There are three main types of incorrect image.

- Images that are positive, but limited or unhelpful for various reasons. Here the brand needs to be expanded to include the attributes, benefits and offerings that are more relevant and more motivating to the marketplace.
- Awareness that is so vague or generic it does not help the place to differentiate itself from the competition. Here the brand needs to be enhanced with more precise, more relevant and more distinctive qualities.

- Images that are out of date and can no longer make productive connections between the current offerings of the place and its current audience. Here the brand needs to be revitalised.

\section{Improvement}

Some images are actually negative. Here the brand needs to be improved, so that the audience is gradually encouraged to shift its perceptions towards the positive attributes, benefits and offerings of the place.

If the negative perceptions are unfounded, they need to be refuted or suppressed. In some cases it is simply better to ignore them. The choice will vary from case to case.

If the negative perceptions are founded in truth, the first thing to do is address the problems and communicate that they are being addressed as soon as real progress can be demonstrated. Then the negative perceptions can either be contextualised, so that the audience understands them better and can keep them in a healthier balance with the positive attributes, or de-emphasised, so that they occupy less space in the audience's mind. Again, the choice will vary from case to case.

\section{The analysis}

Most places fit into several of these categories - in fact, there are often parts of their brand image that belong in all the main groups - so the overall analysis of the state of the brand may present quite a complex picture. 
This picture is further complicated by the fact that world opinion is far from a homogeneous phenomenon. Another critical piece of analysis which, surprisingly enough, governments often fail to undertake is a proper 'map' of the country's key audiences for each of its sectors: trading partners, export markets, political allies, cultural partners, source countries for tourists, talent, students, business visitors and so forth. Of course each of these countries or regions must also be subjected to at least a general demographic analysis (for example, different age groups often differ widely in their perceptions of foreign countries: one of many interesting results from the Nation Brands Index is the observation that younger, poorer and predominantly female French respondents tend to be substantially pro-American, whereas older, better-educated and richer males are generally anti-American).

The analysis may be dauntingly complex, but this should not prevent the solution from being rather simple - as it needs to be if it is to be clearly understood and properly absorbed by the numerous 'stakeholders' in the nation brand, and if it is to guide their behaviour in any way at all, rather than simply end up gathering dust on a shelf somewhere (as many of these initiatives tend to do).

\section{ABOUT UNBALANCED BRANDS}

The brand images of places are usually communicated through a complex mixture of their tourism offerings and promotions, their products or other business activities, their cultural, social and political scene as reflected in the media and their famous and not-so-famous people (the nation brand hexagon, as described in my editorial in Vol. 1, No. 4 of Place Branding, is one way of navigating through the complexity of these difference influences). For example, my own image of Japan comes from a mixture of news stories, fact and fiction, experience with products and services, history and film and literature, visits to the country and meetings with Japanese people, eating Japanese food, watching Japanese politicians on the television and reading about Japanese people in books and newspapers, and so on, over several decades. You could hardly begin to say which of those influences were the main ones, how long it took for me to build my current image of the country, whether it could ever change, or even what my overriding feeling about Japan is today.

But many nations and regions today, especially in developing countries, have brand images that are heavily or even exclusively biased towards tourism: in many cases, tourism has proved to be the only source of revenue which has the potential to lift such places above subsistence levels. In the end, even if a country has nothing to sell people, they can always come and have a look at it.

Such places have brands that are seriously unbalanced: if the main relevance of the place for the majority of people is one single industry, then the way that particular product or sector is marketed - or fails to be marketed becomes the way the whole brand image of the place is built. Such countries are thought of by most outsiders purely as a tourism or leisure destination: they have only ever come across the country in this context; tourism information is their only information about the place; and it is on this basis that they form all their views about it.

This fact makes such places very vulnerable. If the tourism brand declines, it is unlikely that anyone from outside the country will be prepared to believe that it is a good place in which to live 
and work, invest, or buy products from either. They will assume that it has failed as a place. If a catastrophic event, such as the 2004 Indian Ocean tsunami, causes serious damage to the tourism 'product', then the brand image of the place can do little to help provide income from other sources apart from charity.

A nation brand, region brand or city brand that depends too heavily on awareness of a single economic sector, a single product or a single characteristic is one of several examples of a brand that needs expansion, in order to lessen the exposure of the place to risk.

\section{JUMPING IN WITHOUT CRITERIA FOR JUDGING THE BRAND STRATEGY}

A second mistake that I frequently encounter in places looking at branding issues is the failure to establish and agree on adequate selection criteria for the brand strategy itself before embarking on the strategic process. Without such criteria it becomes difficult for people to agree about what is appropriate and workable for the place and what is not; selecting ideas becomes a matter of personal taste and opinion, and when there are so many different stakeholders and different points of view this is a recipe for slowing down or blocking the strategic process.

One example of a criteria set is a simple six-point model I use for evaluating any branding strategy or creative idea. I usually find that if an idea gets 'ticks' in most or all of the parts of this model, it may not be to everybody's taste but it will probably add something to the brand's value and provide a return on the investment made.

The main purpose of these particular criteria is to ensure that the brand vision is utterly compelling and motivating - enough to drive both the people of the place itself and its existing and future target markets to seeing the place in an entirely new and more productive way; to lure them away from the 'comfort zone' of their current perceptions towards something a little unfamiliar and a little more ambitious.

In my experience any good brand strategy should be able to do this, and in order to do so it needs to be six things.

- Creative (surprising, arresting, memorable). Creative is the opposite of boring: this is the factor which perhaps more than any other ensures that the nation, region or city brand stands a chance of being noticed in an increasingly noisy and crowded global marketplace. This may be a matter of execution - one can try to rely on the quality and creativity of the messages used for communications about the place, or the tone of voice with which they are delivered, or the choice of services and case studies that are used to prove the point but this is very much harder to control in a place than in a company since the messengers are so diverse. I think it is always worth trying to see if some robust element of creative thinking can be built into the core brand statement itself. This will always make the place behave and communicate in a more dependably, consistently creative and distinctive way than relying on adding creativity on a message-by-message basis. In other words, one should try to make the creativity conceptual and strategic rather than executional and tactical.

- Ownable (uniquely and unarguably about the place and not anywhere else). Ownability is a combination of truthfulness, credibility and distinctiveness: is it true; is it something that people are prepared to 
accept as true; and it effectively characterises one or more of the factors that objectively distinguish the place from its competitors. The desired future brand of the country, city or region needs to be in some credible way connected to its current brand, or else the task of brand management becomes unfeasible. This must be informed by what the government of the place knows of its audience's perceptions of the place rather than what they themselves believe about the place, because clearly the link has to be made by the audience, not by the government.

- Sharp (highly focused, not generic, telling a very specific and definite story about the place rather than a bland catch-all phrase). There is often a slight air of inter-office memo language that pervades the 'visioneering' work of places, and this is usually because of the need for consensus among a wide group of stakeholders with different interests. What starts out as a fine intention to come up with the idea that everybody loves usually ends up as a desperate struggle to come up with the idea that nobody minds. Ideas that nobody minds are guaranteed to waste all money and all effort expended on them, for the simple reason that they will be of no interest to the target market.

Unavoidably, strong ideas will polarise opinion and often do make people feel a little uncomfortable at first. This quality of the brand is as necessary as creativity to lift it above the ordinary, and to persuade the audience that this is not simply more of the same stuff they are hearing all the time. Lots of countries, cities and regions are starting to work on their brands, and many of them may have genuinely good plans and intentions, but somehow the initiative goes entirely unnoticed. This is often because their strategy just is not daring or striking enough to make an indifferent 'customer' sit up and pay attention; it is all just a bit too general and slippery for people's imaginations to be able to get a good grip on it; in consequence, it might just start to change people's minds about the place if enough weight is put behind it, but it probably will not change their behaviour.

- Motivating (clearly pointing people towards new and different behaviours within government, the private sector and civil society that will lead to a changed image). A brand strategy can be good, true, ownable, believable, sharp, distinctive and creative, but still have no effect whatsoever - and this is usually because it is trying so hard to be good branding that it forgets to be good policy; it is a passive descriptor of the brand rather than an active force for sustaining or changing it. A brand strategy statement is not an advertising slogan. You will never see it on a billboard: it is a key for making people see themselves in a new way, and so behave in a new way, and so eventually be seen in a new way. The test for a viable brand strategy is a simple question: 'Will it make us change the way we behave?'

- Relevant (a meaningful promise to the consumer). Good brands work inside and outside - they are motivating to the population and stakeholders but must be equally so to customers, or else they do not tie in well to the marketing function. Many place brands are too self-referential - a reminder of the place's ethic and purpose rather than a promise to the customer; they offer no explicit relevance to his/her needs, and ultimately give no clear reason to buy.

- Elemental (simple, usable, practical and 
robust enough to be meaningful to many people in many situations over a very long period, and to be practically implementable within the context of each stakeholder's day-to-day business and private objectives). If the brand strategy is too hard to explain or too specific to a particular situation then it cannot function as the single driving force for an entire country or region. Of course the problem with elemental things is that there are not very many of them and they are usually a bit dull: the trick is to engineer a new proposition which is as distinctive, creative, sharp and motivational as if it were a complex and sophisticated argument, but as robust, truthful, simple, universal and universally applicable as a basic element.

\section{ABOUT MEGABRANDS AND SOCIAL CHANGES}

There is no doubt that making places and especially smaller and poorer places - competitive in the global marketplace is a huge challenge today. A modestly enhanced and better-managed version of their current reputation might be of some help to some places, but it will not help a failing brand reverse its decline, or help a poor place sell more products in rich markets, attract major investors, or greatly increase its inbound tourism figures. In coarse commercial terms, places must aim become megabrands if they want to maximise the nation branding effect: far more than places that are simply known to be attractive, they must try to become world famous.

And what makes a megabrand, one of those brands that seem to do far more than just sell, but inspire great loyalty, positive prejudice and lifelong interest? It is certainly not because they advertise so much. As I have often said, a megabrand is one that finds itself, by accident or by design, in the path of major social change.

Countries, cities and regions need to aim to achieve the same effect. The purpose of the brand strategy must be to ensure that the country has what people want and need at the moment when large numbers of people discover what it is they want and need. Place brands must anticipate where the next major social change is going to be, and make sure that the country is correctly positioned in the path of that change, and in a way that provides for the possibility of success into the foreseeable future. It goes without saying that the 'product' itself must also be able to deliver on that promise: so the social changes observed must have some innate relevance to the country's resources, abilities or talents.

\section{ABOUT BORINGNESS}

My favourite definition of insanity is 'continually repeating the same behaviour in the expectation of a different result' (a quote usually attributed to Albert Einstein). There is no question that it is the past and current behaviour of almost all places which causes their brand image: at some level, most places get the image they deserve, and imagining that they can change the brand of the place without changing the way they behave is the height of delusion.

It is not that the general public is stupid or ignorant, or that the place has somehow failed to tell the truth about itself: it is usually that it is not doing enough new things to capture anyone's attention or prove that it has a direct relevance to the lives of the people it is trying to talk to. New and interesting things are the only things that get adequately reported in the media, because they are the only things in which people are always interested. 
— Old boring things are very boring.

- New boring things are fairly boring.

- Old interesting things are fairly interesting.

- New interesting things are very interesting.

This rather dispiriting observation should form the basis of any serious planning about the management of national or regional image. No matter how little one may like it, this degree of absolute objectivity is the primary requirement of any initiative aimed at understanding and dealing with reputation and public opinion.

\section{ABOUT CULTURE AND MAGNETS}

Culture can often play a critical role in moving the current brand image of a country towards its desired brand vision. Culture is the component which is absolutely necessary in order to make any place properly satisfying as a brand, especially in the case of countries which, as I mentioned earlier, suffer from a brand image that is largely or exclusively based on tourism.

Culture is next door to tourism (indeed, cultural tourism is often identified as the highest-yielding and fastest-growing area of tourism), and it is the area that can start to make a connection between people's interest in the place itself and their interest in the life of the place. A rich cultural life makes a complete place rather than just a tourist destination, a place worth visiting at different times of the year, a place with a broader social appeal but particularly to the higher-end, higher-spending, somewhat older and usually well-behaved visitors that most tourist destinations need above all others.

Most moderately developed countries and regions have a range of cultural attractions to offer the visitor in the form of historical and heritage sights; relatively few have attractions that really create a sense of the cultural life of the place. Yet new attractions and events of the right sort are ideal for putting a new lens in front of the country and starting to change people's minds about the kind of place it really is.

Rather than the sort of cultural event that the right kind of person already visiting the country might want to include in their itinerary, what places really need are the kinds of event that will give people a reason to go to the country in the first place. Creativity is what makes the difference between enjoyable events that play a role in enhancing the place and events that create their own market, events that are magnetic and make the place a destination in its own right.

And the raw materials for a rich, varied and attractive cultural life are often lying around, just waiting to be assembled in a new way. What places need are the people with the imagination, the ambition, the creativity and the energy to make these connections, give them life and make extraordinary things happen; they need the encouragement and the moral and financial support to help them to think creatively and act on their creative ideas; in short, the country, more than anything else, needs to build a spirit of creative entrepreneurship.

In order for an event or attraction to become a magnet in its own right, it either has to have mature pulling power, built up through many years of excellence (like the Montreux Jazz Festival, the Burning Man festival in Nevada or the Oberammergau Passion Play), or be so unique and irresistible that its pulling power is intrinsic and born great, and needs only a very short time to become established (like Cirque du Soleil, London's Tate Modern or the Live8 concerts). 
Most of the attractions that appear to be born great are actually helped along by substantial funding, and there is no doubt that a Burj al-Arab, an Eden Project or a Guggenheim Museum can really put an unknown place on the map. But fortunately money is not the only thing that can achieve this effect. There are places and events that manage to pull off the same trick without huge investments in infrastructure or marketing: they are simply magnetic ideas that seize the imagination and are compelling by their very nature. Three good examples of these are listed below.

- The Ice Hotel in Sweden, which cost little to build but became an almost overnight success and, according to the Anholt Nation Brands Index (www.nationbrandsindex.com), is now the best-known tourist attraction in Sweden.

- The Pike Place Fish Market in Seattle, which was just a fish market for about a hundred years until one fishmonger decided to get his shop assistants to juggle with their fish: it is now the city's main attraction and draws tourists (and customers) from all over the USA.

- Isla Mujeres, a small island off the coast of Mexico which was close to destitution until they decided to paint every building on the island using a palette of authentic Mexican colours. The Painting the Island project gained an enormous amount of free global publicity; American cruise ships now regularly stop at the island, and the place has an economy.

What these attractions and others like them all have in common is the fact that they are themselves clear and powerful brands. Their fundamental attraction can be described in a few simple words, and this is in the nature of all good brands: they give people a great story to tell each other. Building a brand (and this is equally true of branding attractions and branding places) is not done by 'selling' directly to the entire marketplace: that is just not feasible. It is done by inventing a proposition that is inherently so original, irresistible and unforgettable that it is simply self-propelling. To set the ball rolling it is only necessary to persuade a few people to try it, like it, and help and encourage them to talk persuasively about it to the much larger number of people they know, and so on.

Marketing experts like to talk about viral marketing, buzz marketing, word of mouth, peer influence and cascade marketing as if they were somehow different from classic marketing, but in fact all good marketing is viral, and always has been. People are the only efficient and cost-effective advertising medium for reaching large numbers of other people. The brand has to be like a little travelling-salesman kit which is given to the limited audience one actually can afford to reach, and which equips them to spread the word on behalf of the brand to millions of other people. And they will do this for free, rather effectively, time and time again, simply because they want to, and because somebody has succeeded in firing their imagination.

'How far would I go just to see that?' is a good measure of the magnetism of an idea, and a crucial test question for any new event or attraction that is being proposed. Unless it produces and impeccably executes two 100-mile ideas for every 20-mile idea, the region or country is unlikely to change its image.

Culture includes sport: Hong Kong has achieved a lot of brand capital from the revival of its famous dragon boat races, and there is no reason why any other country or region should not revive or invent some unique indigenous 
sports which reflect some attribute of the place and the life of its people.

The key point is that not having dozens of world-class events or attractions does not mean that a place is doomed to fare less well than the places that do: one can build heritage, invent attractions, make a place magnetic. And there is nothing at all shameful or dishonest about inventing heritage (as long as one does not make false claims about its origins, of course): after all, even old things were new once, and part of the art of being a good ancestor is starting lots of valuable traditions in one's own lifetime so that one's descendants can benefit from them later.

Making magnetic attractions is often a matter of taking a basic cliché that everyone knows about the place as the starting point (eg Sweden is cold, Mexico is colourful, Seattle is a lively fishing port, Hong Kong is on the water and Chinese culture is full of dragons). Then one uses the human and natural capital that is lying around and sculpts it together to make a magnet. And of course there is nothing that says every idea has to be on a huge scale: even a tiny, perfect idea like a new way of selling fish plays its part in branding the city, region or country. Not every idea can be a 100-mile or 1,000-mile idea, but even a 10 -mile or 20-mile idea helps brand the place: the important thing is that they are all aligned, all pointing the same way, all telling the same story about the place.

Innovation is at the heart of creating cultural attraction in a place. Clearly, it is not something that one can just hope will come along: it has to be stimulated and it needs the right people and the right conditions to flourish. For this reason, one of the functions of the body that manages the nation or region brand must be to create innovation groups whose only job is to produce a constant stream of innovative ideas which can then be circulated around the companies, groups and individuals who might want to add to them, combine them with their own ideas or pick them up and give them a try.

The way this is achieved will vary from place to place and from sector to sector, but it is wise not to put too much faith in the popular management creed that everyone is innately creative and the only thing that is stopping every last person in the organisation from producing dozens of epoch-making ideas every day is the lack of a proper facilitator, the right leadership or management system, or the perfect environment. Experience in both the private and public sectors tends to suggest that usable creativity is a faculty possessed by a small minority of exceptionally gifted people; that it is considerably sharpened by hard work and good technique; and that no technique on earth can 'release' that creativity in people who do not have it in the first place. So the effectiveness of such teams is very largely to do with who their members are, and nothing much else.

Good creative ideas, it is true, are often very simple, but this is deceptive. Just because anybody can understand them or act on them does not mean that anybody can come up with them: in fact, quite the contrary.

The Pike Place Fish Market in Seattle is a good example of the kind of simple innovation that can completely galvanise an ordinary business and turn it into a 100-mile magnet (in the case of Pike Place it is actually a 3,000-mile magnet, because people regularly come from across the country just to see it). There is a particular kind of attitude that is necessary in order to achieve this sort of brand turnaround, and it is worth quoting an employee of Pike Place recounting a very telling conversation he 
had with the founder just after they launched:

'We asked him: "How are we going to become world famous? We don't have any money to advertise!" Jim told us we didn't have to know how to become world famous. He told us that when you're generating a powerful vision, the future just unfolds. He told us not to believe in it. We just had to be it. He pointed out that there's a big difference between a belief about something and the actual thing itself. Muhammad Ali didn't say, "I believe I am the greatest." He said, "I am the greatest.", (www.pikeplacefish.com/ aboutus/aboutus_page4.htm)

That is the spirit that any wise government will be looking out for and ultimately trying to breed - when starting to brand a country, a region or a city.

\section{THE MOTIVATIONS OF BRAND LEADERS}

The brands of places need to be managed for the very long term, and there are four basic qualities which I see as the essential motivations for the people who look after them and lead the brand management process. These qualities all sound rather simple and rather old-fashioned: they are wisdom, patience, imagination and care.

Wisdom is essential because it is often very hard to make the right choices between short-term promotion and long-term brand building, especially when there is immediate economic pain.

Patience is necessary because the brands of places move very slowly. The brand of the country that one inherits today may be the cumulative effect of centuries of management and mismanagement, some of it deliberate and most of it not. It will certainly take years, if not decades, to change it.

Imagination is important because only innovation and creativity can create real progress, change the brand and keep it healthy. 'Management' is a dull word indeed for what places really need, but there must always be a proper balance between the creative spark and the steady hand on the tiller. This balance must be reflected in the body that looks after the brand.

Care is important because only people who have the best interests of the place at heart can be trusted always to do the right thing for its ecology, economy and community. One can rearrange those three words endlessly, trying to put them in the right order, but in fact there is no right order: all three of them have exactly equal priority, and the key to managing the brand of the country is to create a structure that is able and willing to hold these three in perfect equilibrium.

\section{POETRY, CEREMONY AND RITUAL}

Most people naturally assume that the desirable attributes of a nation branding strategy are efficiency, inclusiveness, consensus, vision, expertise and so forth, but qualities such as poetry, ceremony and ritual, even romance, can play a significant part in the success of the venture.

This may sound a little whimsical, but there is a practical reason for it. If people are to take their tasks seriously - and few things are more serious for a place than its reputation and the implications this has for its economic, social and cultural development - then it is essential that the importance of those tasks is fully felt by everyone, and fully communicated. The usual methods for communicating importance and gravity in our modern world - portentous phrases in boring documents passed around in dull offices - are singularly ineffective. All they usually produce, not 
surprisingly, are boring conclusions that nobody objects to and which change precisely nothing.

Far better results can be achieved when we turn instead to the techniques which our (in some ways) wiser forebears employed when it was necessary to make things feel important: ritual, ceremony, poetry and even a little hocus-pocus. Instead of meeting in committees in meeting rooms, why not create a ritual of meeting in some special public place; instead of naming the decision-making body in some predictable bureaucratic way, why not give it an imaginative and inspiring title with a potent historical reference; instead of just listening to what economists, pollsters, public affairs specialists and government officials think the future image of the country should be, why not also consult with writers, poets, film makers, comedians?

By giving the circumstances and the make-up of the strategic process a little sideways twist, the chances of it developing something genuinely new and genuinely powerful are vastly increased. It is also a good way of making the members of the group understand, and feel, that this is not 'business as usual': they are expected to produce more than procedure. They need to produce extraordinary things, and this is very much harder to achieve when you are in an ordinary mood doing ordinary things in ordinary surroundings.

It is also designed to lighten the mood, even though the issues may be deadly serious. The best solutions to deadly serious problems are nearly always creative, imaginative, daring. They are sometimes even fun. The process is designed to make people feel more pride in their city, country or region and in what they are doing. There is little glamour in being on a committee in a committee room, but doing special things with special people in a special place for a special reason feels like an honour and a privilege, and so achieves superior results every time.

When the ultimate 'consumer' of a piece of policy is simply other officials, other departments or other governments, then arguably there is no need for that policy to be anything other than efficient and effective. But nation branding, city branding and region branding are rather different, because their ultimate 'consumer' is the general public; the policy has to compete for the public's fleeting and precious attention and interest in a very crowded, very noisy and very exciting public sphere of media, commerce, communication and attention.

For this reason, efficient and effective is only the beginning: the brand also needs to persuade, to inspire and to motivate. To achieve such lofty aims, 'policy as usual' is simply not enough.

\section{Simon Anholt Managing Editor}

\section{Reference}

Maslow, A. H. (1965) 'Eupsychian Management: A Journal', R. D. Irwin, Homewood, IL. 